http://jmscr.igmpublication.org/home/ ISSN (e)-2347-176x ISSN (p) 2455-0450

crossref DOI: https://dx.doi.org/10.18535/jmscr/v8i4.20

\title{
Is Unimanual Phacoemulsification a Sensible Technique, as an Alternative procedure or a Transitional step Towards Bimanual Phacoemulsification for the Beginners?
}

\author{
Author \\ Dr K.M Suresh, MBBS,MS (OPH) \\ Medical Director, Vidya Eye Hospital, Vijayanagar, Bangalore 560040 \\ Formerly: Asst.Prof. KIMS Bangalore; Asso. Prof. RRMCH Bangalore; Prof. and HOD BGS GIMS \\ Bangalore, India
}

Abstract
Aim of this study is to find out whether it is useful to do unimanual technique, instead of straight away
proceeding to bimanual technique while converting from Small Incision Cataract Surgery(SICS), to
Phacoemulsification technique, or from Extra capsular Cataract Exctraction (ECCE) to
Phacoemulsification
Materials and Methods: Consisted of a prospective study, of 100 patients, with cataract, who were
operated by the Unimanual technique of (explained exclusively in our study) phacoemulsification with
intraocular lens implantation (IOL).
Results of this Unimanual technique were assessed and tabulated to appraise and instruct the beginners
of phacoemulsification to arrive at the appreciable and accurate accomplishment of the
phacoemulsification procedure.
Conclusion was that the unimanual technique of phacoemulsification is definitely a sensible, and an apt
procedure to be followed before proceeding to a bimanual technique of phacoemulsification and can
also be used as an alternative method for bi-manual phacoemulsification.

Relevance of the study

In most of the teaching institutes the postgraduates do not start the bi-manual technique of phacoemulsification as their primary procedure of learning cataract extraction.

They are in fact allowed to practice the primary steps of SICS and/or ECCE. Later on they will be allowed to perform SICS or ECCE independently, under the supervision of a senior ophthalmologist.
As soon as they learn these two basic procedures they will be eager to learn bi-manual technique of phacoemulsification, which needs a lot of skill and dexterity. Instead of straight away venturing into this bimanual technique which demands extraordinary skill, there is necessity for an intermediate step, which requires less skill but helps to attain the same result which is expected in the bi-manual technique of phacoemulsification 
done by an experienced ophthalmologist. Hence this study, thus smoothens the learning curve of an aspirant ophthalmologist, while converting from the basic techniques of SICS or ECCE to $\mathrm{Bi}$ manual Phacoemulsification procedure.

\begin{abstract}
Aim
Aim of the study is to find out whether the intermediary step of uni-manual technique of phacoemulsification is possible at all, if possible, is it scientific enough to achieve good result, so that it can be passed on to the progeny, as a sensible technique to be safely performed on the cataract patients. Aim of this study was also to find out whether this technique forms an easy and convenient stepping stone to perform bi-manual phacoemulsification on a later date. Assessment of benefit of these procedure also were done to see whether this method can be recommended to be done independently, rather than promoting this procedure as a stepping stone for bi- manual phacoemulsification. The results, thus obtained and tabulated, were utilized to guide the beginners to help in achieving best possible results in phacoemulsification
\end{abstract}

\section{Materials and Methods}

The patients selected for this study were the patients who walked into the out-patient departments of Vidya Eye Hospital Vijayanagar Bangalore. The patients in the study had come for cataract operation from January 2010 to June 2017. Unimanual technique of Phacoemulsification was done on all these 100 patients.

The method followed in our exclusive method of unimanual phacoemulsification was as described below. The operations were performed under topical anaesthesia. In all the cases clear corneal incisions were made. The study included both the groups, which underwent, rigid $5.25 \mathrm{~mm}$ optical diameter Intraocular lenses and foldable lenses.
The clear corneal incision was made at 12 'o' clock meridian by using $2.8 \mathrm{~mm}$ keratome blade, tryphan blue was injected into the anterior chamber to stain the anterior capsule, through the same 12 o clock incision, viscoelastic substance was used to form the Anterior Chamber. Cystitome made out of 26 gauze needle was used in all the cases to do CCC (Continuous curvilinear capsulorhexis). Hydro dissection, hydrodelineation and hydrodelamination were done as described in the standard textbooks.

Later on phacoemulsification was done followed by intraocular lens implantation.

Phacoemulsification procedure was conducted through the 12 ' $\mathrm{O}$ ' clock meridian. Trenching of the nucleus was done from 12 'o' meridian to 6 'o' clock meridian of the nucleus of the crystalline cataractous lens. 90 degree rotation of the nucleus was achieved either through the phacoemulsifier probe, or lens dialer. In some cases the rotation was achieved by using cystitome prepared with $26 \mathrm{G}$ needle. Later trenching is continued so as to produce four quadrants. In cases where the lenses are hard and leathery an iris repositor with $26 \mathrm{G}$ needle were used to break the nucleus into pieces. These pieces are later phacoemulsified through phaco 2 module of the phacoemulsifier. The cortical matter was removed completely by irrigation and aspiration. The cortical matter which is located at 12 'o' clock meridian was removed by using bent bi-way cannula. The whole procedure and all the manouvres were done through the $2.8 \mathrm{~mm}$ incision done at 12 'o' clock meridian. 
Chart describing the salient differences between the uni-manual procedure followed in our study and the standard Bi-manual phacoemulsification techniques

\begin{tabular}{|c|c|c|}
\hline Particulars & Uni-manual & Bimanual \\
\hline Basic Technique & $\begin{array}{l}\text { Only one hand of the surgeon being active } \\
\text { during phacoemulsification. The other hand } \\
\text { engaged only in stabilization of globe. }\end{array}$ & Both the hands are active \\
\hline Anaesthesia & Topical - Preservative free $2 \%$ Xylocaine & Topical- Preservative free $2 \%$ Xylocaine \\
\hline Incision & $2.8 \mathrm{~mm}$ incision only at $12 \mathrm{o}$ clock & $\begin{array}{l}2.8 \mathrm{~mm} \text { incision at } 12 \mathrm{o}^{\prime} \text { clock; } 1.5 \mathrm{~mm} \\
\text { incision at } 3 \mathrm{o}^{\prime} \text { clock and } 9 \text { o, clock (side } \\
\text { ports) }\end{array}$ \\
\hline $\begin{array}{lr}\text { Removal and } & \text { Re } \\
\text { introduction } & \text { of } \\
\text { Phacoemulsifier } & \end{array}$ & $\begin{array}{l}\text { Removal of phacoemulsifier after initial } \\
\text { trenching, done to rotate the nucleus by using } \\
\text { cystitome/dialer. Re introduction of } \\
\text { phacoemulsifier to complete trenching }\end{array}$ & $\begin{array}{l}\text { Once the phacoemulsifier is introduced, it } \\
\text { is removed only after the complete } \\
\text { phacoemulsification. Rotation of nucleus is } \\
\text { simultaneously assisted with } \\
\text { cystitome/chopper }\end{array}$ \\
\hline Nucleus division & Done after $90 \%$ trenching is completed & $\begin{array}{l}\text { Done after } 65 \% \text { to } 75 \% \text { of trenching is } \\
\text { done }\end{array}$ \\
\hline $\begin{array}{l}\text { Operative } \quad \text { Wound } \\
\text { leakage }\end{array}$ & Not observed & Observed through free side ports \\
\hline $\begin{array}{l}\text { Stromal hydration of } \\
\text { incision }\end{array}$ & Was not done & Was done for side ports \\
\hline Cortical wash & $\begin{array}{l}\text { Done by using single incision (12o'clock). } \\
\text { Bent cannula for cortical matter at } 12 \text { o' clock }\end{array}$ & $\begin{array}{l}\text { Bimanual irrigation and aspiration through } \\
3 \text { o' clock and } 9 \text { o' clock side ports }\end{array}$ \\
\hline Time taken & Average 35 minutes & Average 25 minutes \\
\hline Assessment & $\begin{array}{l}\text { Good technique while converting from SICS to } \\
\text { phacoemulsification, for beginners }- \text { no } \\
\text { complications are encountered in this } \\
\text { transitional step. }\end{array}$ & $\begin{array}{l}\text { Good to follow only after mastering } \\
\text { Phacoemulsification. }\end{array}$ \\
\hline
\end{tabular}

The cases which were treated by this uni-manual technique were postoperatively assessed by using the following parameters, stability of the anterior chamber during and after the procedure, corneal clarity, posterior capsular rupture, residual cortical matter, post-operative vision after $7^{\text {th }}$ postoperative day, time duration for the surgical procedure.

\section{Results}

It is very important in this study to assess the results, carefully, critically and rather crucially so that we will be able to arrive at a noncontroversial conclusion so that it will be helpful for the beginners to do phacoemulsification confidently with a clear hope of achieving good results.

\begin{tabular}{|l|c|}
\hline Post-operative Vision & Number of Patients \\
\hline $\begin{array}{l}\text { 6/6 unaided vision after } 7^{\text {th }} \text { Post- } \\
\text { operative day }\end{array}$ & 85 \\
\hline 6/6 after correcting residual power & 10 \\
\hline BCVA less than 6/12 & 5 \\
\hline
\end{tabular}

\begin{tabular}{|l|c|}
\hline Parameters & Number of patients \\
\hline Corneal Striae & 5 \\
\hline Posterior Capsular Tear & 6 \\
\hline Uneventful & 89 \\
\hline Dislocation of Lens into Vitreous & 0 \\
\hline
\end{tabular}

After careful assessment of the results of all the 100 cases in our study, we observed that 85 patients had $6 / 6$ unaided vision after the $7^{\text {th }}$ postoperative day. 15 patients had sub normal unaided vision, out of which 10 patients were able to attain $6 / 6$ vision after correcting the residual power. 5 patients in our study had best corrected visual acuity of $6 / 12$. The reason for this lesser vision was either lens tilt astigmatism, and recurrent uveitis causing mild macular oedema. 


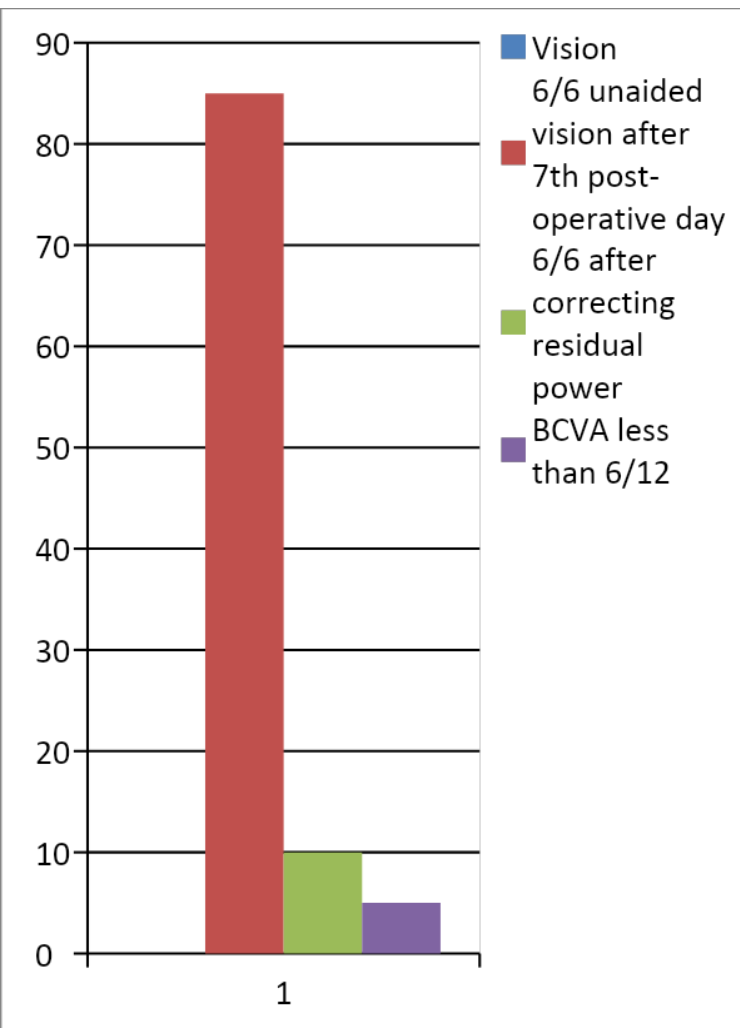

Figure 1.X- Postoperative Vision Y- no. of patients

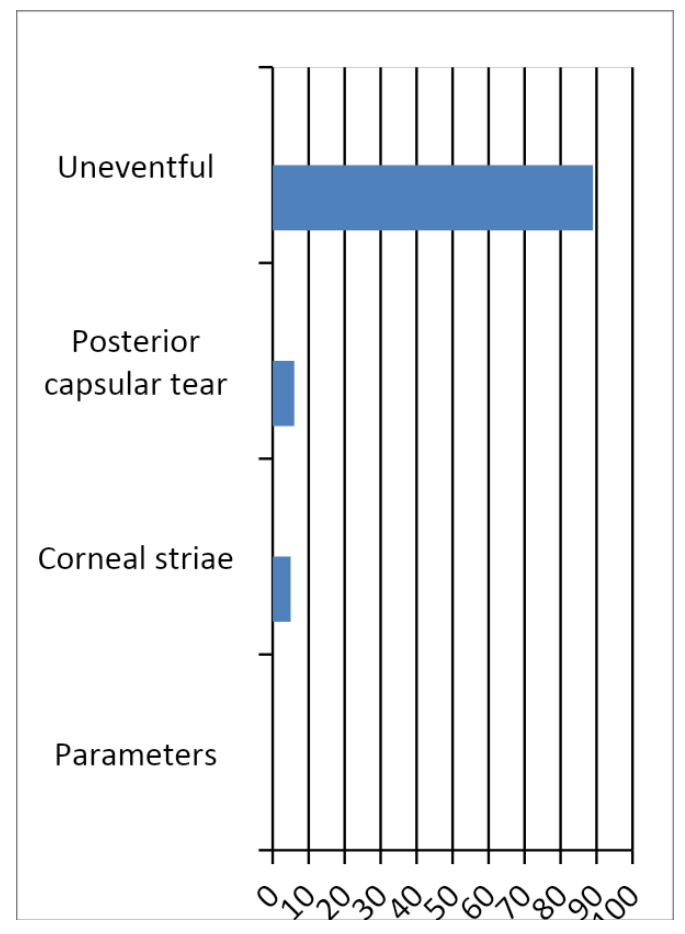

Figure 2 X Axis - No. of patients Y-Parameters

\section{Discussion}

This procedure needed a lot of determination and courage to execute, as it is an innovative phacoemulsification method which is not acceptable by the experts in the field. Anyway we designed this clinical study purely for the benefit of the beginners so that it becomes a strong stepping stone for them to confidently move on to the bimanual technique easily.

As the procedure was less cumbersome and highly convenient the residents found it very easy to perform. As the co-ordination of both the hands was not necessary, the beginners found it much easier to get adjusted to the procedure of phacoemulsification when they switched over from the Small Incision Cataract Surgery to Phacoemulsification procedure. In fact it was considered as a good transitional step in their journey to bimanual phacoemulsification.

\section{Conclusion}

So, with this study most of the qualified ophthalmologists who are already practicing bimanual phacoemulsification and the residents who planned to learn phacoemulsification for the first time, categorically agreed that it is a convenient transitional step towards the bimanual phacoemulsification procedure.

Thus our study concluded that unimanual phacoemulsification is a sensible transitional step towards the procedure of bimanual phacoemulsification. Hence it can be recommended for the beginners, and can also be used as an independent procedure to perform phacoemulsification. This technique also helps in mitigating and decreasing the complications of phacoemulsification when the beginners try to learn this new technique.

\section{References}

1. Bimanual microincision versus coaxial phacoemulsification cataract surgery, Saber H El-Sayed, Amin F Ellakwa, Nermeen M Badawi, Abeer M Wahba, Department of Ophthalmology, Faculty of Medicine, Menoufia University; Shibin ElKom Ophthalmology Hospital, Menoufia Governorate, Menoufia, Egypt

2. The phacoemulsification learning curve: per-operative complications in the first 
3000 cases of an experienced surgeon. Martin KR1, Burton RL. Eye (London) Apr;14 Pt.2: 190-5

3. The Resident Surgeon Phacoemulsification Learning Curve Bradley Randleman, MD; Jeremy D. Wolfe, MD; Maria Woodward, MD; et al Michael J. Lynn, MS;D. Hunter Cherwek, MD; Sunil K. Srivastava, MD, Author Affiliations Article Information Arch Ophthalmol. 2007;125(9):12151219. doi:10.1001/archopht.125.9.1215

4. Kurz S, Krummenauer F, Gabriel P, Pfeiffer N, Dick HB. Biaxial microincision versus coaxial small-incision clear cornea cataract surgery. Ophthalmology 2006; 113 :1818-1826.

5. Jean, Claude. Bimanual micro-incision phacoemulsification the way forward. l'ophthalmographe 2005; 22 :4-5.

6. Hayashi K, Hayashi H, Nakao F, Hayashi F. Risk factors for corneal endothelial injury during phacoemulsification. $\mathrm{J}$ Cataract Refract Surg 1996; 22 :10791084.

7. Fine IH, Packer M, Hoffman RS. New phacoemulsification technologies. J Cataract Refract Surg 2002; 28:1054-1060.

8. Fishkind WJ. Course on advanced concepts in phacoemulsification. Highlight of ASCRS 1998; 3: 11

9. Rowden A, Krishna R. Resident cataract surgical training in United States residency programs. J Cataract Refract Surg. 2002;28(12):2202-2205.

10. Albanis CV, Dwyer MA, Ernest JT. Outcomes of extracapsular cataract extraction and phacoemulsification performed in a university training program. Ophthalmic Surg Lasers. 1998; 29 (8):643-648.

11. Allinson RW, Metrikin DC, Fante RG. Incidence of vitreous loss among thirdyear residents performing phacoemulsification. Ophthalmology. 1992;99(5): 726-730.
12. Allinson RW, Palmer ML, Fante R, Stanko M. Vitreous loss during phacoemulsification by residents [letter]. Ophthalmology. 1992;99(8):1181.

13. Blomquist PH, Rugwani RM. Visual outcomes after vitreous loss during cataract surgery performed by residents. J Cataract Refract Surg. 2002;28(5):847852.

14. Corey RP, Olson RJ. Surgical outcomes of cataract extractions performed by residents using phacoemulsification. J Cataract Refract Surg. 1998;24(1):66-72

15. Cotlier E. Phacoemulsification by residents [letter]. Ophthalmology. 1992;99 (10): 1481-1482.

16. Cruz OA, Wallace GW, Gay CA, Matoba AY, Koch DD. Visual results and complications of phacoemulsification with intraocular lens implantation performed by ophthalmology residents. Ophthalmology. 1992;99(3):448-452.

17. Hollander DA, Vagefi MR, Seiff SR, Stewart JM. Bacterial endophthalmitis after resident-performed cataract surgery. Am J Ophthalmol. 2006;141(5):949-951.

18. Karp KO, Albanis CV, Pearlman JB, Goins KM. Outcomes of temporal clear cornea versus superiors clearl tunnel phaco emulsification incision sina university. 